
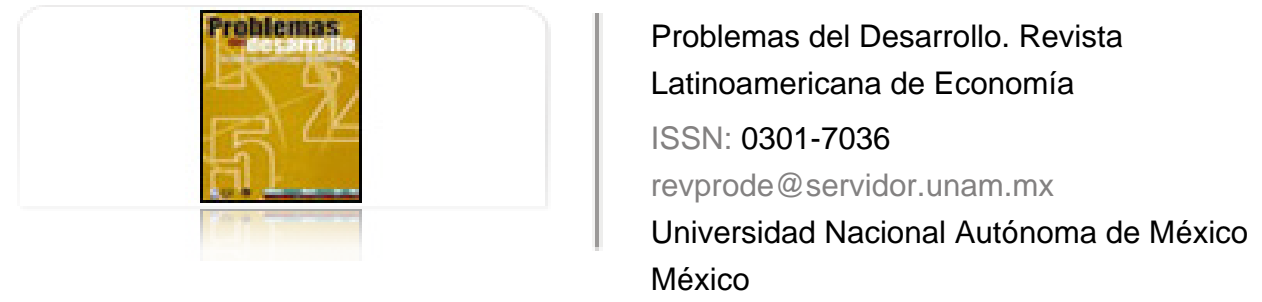

Guerra-Borges, Alfredo

Sobre la teoría neoclásica de la integración

Problemas del Desarrollo. Revista Latinoamericana de Economía, vol. 34, núm. 133, 2003, pp. 9-27

Universidad Nacional Autónoma de México

Distrito Federal, México

Disponible en: http://www.redalyc.org/articulo.oa?id=11825949008

- Cómo citar el artículo

- Número completo

- Más información del artículo

- Página de la revista en redalyc.org

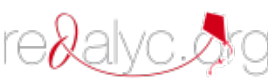

Sistema de Información Científica

Red de Revistas Científicas de América Latina, el Caribe, España y Portugal Proyecto académico sin fines de lucro, desarrollado bajo la iniciativa de acceso abierto 


\title{
SOBRE LA TEORÍA NEOCLÁSICA DE LA INTEGRACIÓN
}

\section{Alfredo Guerra-Borges*}

Fecha de recepción: 17 de septiembre de 2003. Fecha de autorización: 30 de octubre de 2003.

\section{Resumen}

El artículo trata de los orígenes del pensamiento neoclásico, en especial, lo relativo a la integración económica (propiamente sobre el tema central de sus reflexiones que fue la unión aduanera). Se analiza, además, el desarrollo de las ideas pioneras de Jacob Viner y sus continuadores, las discrepancias iniciales y la creciente insuficiencia de la teoría neoclásica para abordar las nuevas formas de integración económica.

Palabras clave: teoría neoclásica, integración económica, liberalismo económico, uniones aduaneras.

\begin{abstract}
This article refers to the origins of neoclassic thinking regarding economic integration (specifically on the central theme of its reflections which was the customs union). The article also addresses the development of the pioneering ideas of Jacob Viner and his followers, the initial discrepancies and the increasing insufficiency of neoclassic theory to address new forms of economic integration.
\end{abstract}

Key words: neoclassic theory, economic integration, economic liberalism, customs unions.

\footnotetext{
* Investigador del Instituto de Investigaciones Económicas (IIEC UNAM).
} 


\section{Résumé}

L'article porte sur les origines de la pensées néo-classique pour ce qui concerne l'intégration économique (plus spécialement sur le thème central de leurs réflexions qui fut l'union douanière). Cet article traite également du développement des idées pionnières de Jacob Viner et ses adeptes, les différends initiaux et l'insuffisance croissante de la théorie néo-classique pour aborder les nouvelles formes de l'intégration économique.

Mots-cléfs: théorie néo-classique, intégration économique, libéralisme économique, unions douanières.

\section{Resumo}

$O$ artigo trata das origens do pensamento neoclássico sobre a integração econômica (em especial sobre o tema central das suas reflexões, a saber, a união alfandegária). Também trata do desenvolvimento das idéias pioneiras de Jacob Viner e seus seguidores, as discrepâncias iniciais e a crescente insuficiência da teoria neoclássica para abordar as novas formas da integração econômica.

Palabras chave: teoria neoclássica, integração econômica, liberalismo econômico, união alfandegária. 


\section{Una actualidad contradictoria}

uando en 1991 apareció nuestro libro Integración de América Latina y el Caribe ${ }^{1}$ hacía mucho tiempo que la bibliografía latinoamericana de la integración económica regional no prestaba atención, por no considerarlo necesario, a la teoría neoclásica de las uniones aduaneras. Era difícil encontrar obras o textos docentes que se interesaran en hacer una presentación de sus características. Por tal razón, incluir un capítulo sobre el particular pudo haber dejado la impresión de que no pasaba de ser un ejercicio de interés puramente académico y, aun así, entre un círculo más bien reducido. Pero ahora, a la vista de la evolución de la integración latinoamericana en los años noventa, puede afirmarse que la teoría neoclásica de la integración tiene renovada actualidad por dos razones contradictorias y una supletoria. Por una parte, en esos años, los numerosos acuerdos suscritos por doquier en América Latina tienen en común con la teoría tradicional que su raíz es el liberalismo económico, aunque lo aplican a su manera; y, además, algunos principios de la teoría tradicional pueden utilizarse metodológicamente como instrumentos evaluativos de los efectos de la integración. Pero, contrario sensu, el renovado interés en la presentación de la teoría tradicional de las uniones aduaneras se debe a que los procesos de integración contemporáneos, sobre todo los más importantes, se distancian radicalmente de la teoría tradicional de las uniones aduaneras y la comprensión de sus orígenes y consecuencias, por lo tanto, sólo es posible recurrir a las contribuciones de la nueva teoría del comercio internacional. De lo que se concluye que a la fecha no contamos con una nueva teoría de la integración.

La razón supletoria es poner de manifiesto al público latinoamericano, especialmente a los estudiantes, lo que acaba de indicarse pues, no obstante su obsolescencia, la teoría tradicional de las uniones aduaneras sigue firmemente arraigada en influyentes organismos internacionales. No hay que olvidar que las críticas del Banco Mundial al MERCosuR en 1997, claramente recordaron los argumentos de la teoría tradicional, de estirpe neoclásica.

Con la teoría tradicional de las uniones aduaneras ocurre como con la teoría del comercio internacional en la que sigue teniendo validez el principio de las ventajas comparativas como explicación de algunas especializaciones en el intercambio, no obstante que es imposible entender el comercio internacional contemporáneo sin apartarse de sus bases teóricas tradicionales. Más claramente, numerosas exportaciones pueden explicarse con base

Alfredo Guerra Borges, Integración de América Latina y el Caribe, México, Instituto de Investigaciones Económicas, 1991; primera reimpresión en 1997. 
en el principio ricardiano de las ventajas comparativas, pero de otras tantas su origen no sólo no está ahí sino que pueden obedecer a políticas gubernamentales o de las mismas empresas transnacionales. Por supuesto, en el comercio internacional todo participante sabe que tiene determinadas ventajas que lo hacen "comerciable". No es algo tan obvio lo que se tiene en mente sino más bien con cuál teoría del comercio internacional puede explicarse una u otra corriente de intercambio.

\section{El punto de partida}

Los procesos de integración económica regional que dieron origen al BENELux (Bélgica, Holanda y Luxemburgo), y más tarde a la Comunidad Europea del Carbón y del Acero en 1953, la Comunidad Económica Europea (CEE) o Mercado Común en 1958, la Asociación Europea de Libre Comercio en 1960 y la posterior ampliación de la CEE con el ingreso del Reino Unido, Irlanda y Dinamarca en 1972, despertaron gran interés en el mundo académico europeo, particularmente en Inglaterra. Entre 1950 y 1965 el trabajo teórico se interesó particularmente por los efectos económicos del paso de un sistema de protección arancelaria a una unión aduanera, mientras que a partir de 1965 la indagación teórica buscó una explicación de los motivos racionales que se podían invocar para constituir uniones aduaneras.

En un ensayo publicado en 1972, Krauss resumió la situación de la siguiente manera: "La cuestión de la racionalidad económica de las uniones aduaneras ha sido el tema teórico del último decenio, de igual manera que en el anterior el tema fundamental, definido explícitamente por Jacob Viner, fue si la unión aduanera representaba un movimiento hacia un comercio más libre o hacia una mayor protección". ${ }^{2}$ Desde entonces se han incorporado al análisis otros elementos económicos que la evolución del comercio internacional fue evidenciando $y$, en consecuencia, el planteamiento neoclásico gradualmente ha tenido que ceder terreno a la incorporación de otros aportes.

Con anterioridad a la contribución fundamental de Viner, ${ }^{3}$ la cuestión de las uniones aduaneras y sus consecuencias económicas ya había despertado el interés de otros autores. Cournot había señalado en los años veinte que la eliminación de las barreras arancelarias tenía efectos sobre la eficiencia y la equidad, ${ }^{4}$ pero no se detuvo a hacer más profundas consideraciones. Posteriormente, Knut Wicksell y otros autores se ocuparon de los aspectos económicos de las uniones aduaneras pero tampoco hicieron un análisis completo de su problemática. Este vacío fue llenado hasta el año 1950, cuando se publicaron los trabajos

2 Melvyn B. Krauss, "Desarrollos recientes de la teoría de la unión aduanera: una reseña interpretativa", en Integración económica, S. Andic y S. Teitel (compiladores), México, Fondo de Cultura Económica, 1977, p. 54. Advertencia: A menos que se indique otra fuente los trabajos citados en este capítulo referidos en particular a la teoría neoclásica de la integración han sido tomados de Andic y Teitel. Por consiguiente, bastará decir en cada caso: "en op. cit.".

Jacob Viner, The customs union issue, New York, Carnegie Endowment for International Peace, 1950.

4 Auguste Cournot, Recherches into the Mathematical Principles of the Theory of Wealth, New York, MacMillan, 1927. 
de Herbert Giersch, ${ }^{5}$ Maurice Byé ${ }^{6}$ y Jacob Viner. El primero se ocupó principalmente de los problemas de localización de la unión aduanera, aplicando a ésta la teoría de la localización elaborada por Weber y Lösch. Por su parte Byé estudió los problemas de la creación y la desviación de comercio, aunque sin emplear estos conceptos — cuya paternidad corresponde por entero a Viner-, y revisó algunos problemas de las políticas que debían observarse en una unión. Pero fue el análisis de Viner y los conceptos de creación y desviación de comercio que él introdujo, asociándolos con el efecto sobre el bienestar mundial, los que muy pronto tuvieron aceptación general y se incorporaron definitivamente al léxico de la integración económica.

\section{Digresión sobre el concepto de bienestar}

En lo que sigue, habrá de notarse la profusa referencia al bienestar, sobre todo mundial, en la obra de Jacob Viner — quien sentó las bases de la teoría neoclásica de las uniones aduaneras - y de sus continuadores al punto de constituirse en el centro de la evaluación positiva o negativa de los efectos de la integración. No obstante, no hay en sus trabajos un señalamiento preciso del significado con que usaban el término, por lo que el lector contemporáneo lo sobreentiende atribuyéndole el sentido que en general tiene en nuestros días, de alguna manera relacionado con el desarrollo económico. Por tal motivo haremos esta breve digresión.

El concepto aparece ya en Aristóteles para quien, en último análisis, el hombre realiza sus acciones con vistas a alcanzar aquel "bienestar total que es suficiente por sí solo para hacer deseable la vida, una vida libre de toda indigencia y llena de las más vivas satisfacciones". ${ }^{7}$ A partir de los fisiócratas, en el siglo xVIII, la idea de que el crecimiento económico debe servir para mejorar la condición humana se impuso gradualmente, y de los fisiócratas esa idea pasó a Adam Smith y se incorporó a su obra trascendental.

En épocas más recientes, la expresión economía del bienestar designa el amplio campo de investigación en el que se incluyen

los intentos dirigidos a determinar si puede definirse en alguna forma un máximo social, si existe de hecho y con qué sistema de precios y de distribución de la renta puede obtenerse. Comprende, en otras palabras, los problemas de la mejor imposición, de la justicia económica, de la iniciativa social respecto de la individual, así como el de la mensurabilidad de las comparaciones interpersonales y de la redistribución de la utilidad, temas todos ellos que son el objeto de una inmensa literatura y de un interés nunca decaído. ${ }^{8}$

\footnotetext{
Herbert Giersch, "Economic Union between Nations and the Location of Industries", Review of Economic Studies, núm. 2, 1949 1950.

Maurice Byé, "Unions Douanières et Dones nationales", Economie Appliqué, París, enero marzo, 1950. Centro de Estudios Filosóficos Gallarate, "Aristóteles", Diccionario de filósofos, Madrid, Rioduero, 1986.

Diccionario de economía política, dirigido por Claudio Napoleón, Madrid, Castilla, 1962, p. 85, citando a O. Morgenstern.
} 
Sin embargo, "además de vasta la literatura sobre el tema es extremadamente controvertida y no exenta de ambigüedades o contradicciones". 9

Visiblemente, el concepto de bienestar de la teoría tradicional de las uniones aduaneras no está referido a temas como los indicados, por lo que adelantamos la hipótesis de que más bien lo que se tenía presente era el bienestar como suma de las satisfacciones obtenidas en el consumo individual gracias a la óptima asignación de los recursos entre distintos usos alternativos. Viene al caso recordar que una característica de la teoría neoclásica es que si los sujetos económicos son "capaces de realizar elecciones racionales con miras a la maximización de un objetivo individual, como la utilidad o el beneficio, forzosamente deben ser individuos [...] Así, desaparecen de la escena los sujetos colectivos, las clases sociales y los cuerpos políticos, que (de manera frontalmente opuesta) los mercantilistas, los clásicos y Marx situaron en el centro de sus sistemas teóricos". ${ }^{10}$

Pigou, uno de los autores más destacados de la teoría del bienestar, admitió el postulado de que el bienestar está compuesto por estados psíquicos y por sus relaciones, lo que subraya la visión individualista del neoclasicismo, así que el análisis de las causas de su incremento o disminución quedó circunscrito "a aquella parte del bienestar social que puede ser relacionada, directa o indirectamente, con el metro del dinero". ${ }^{11}$ A esta parte se le designó bienestar económico, cuyas fronteras con el bienestar en sentido general son sumamente imprecisas. Finalmente, habremos de encontrar más adelante, en la evolución de la teoría de las uniones aduaneras, que el primer distanciamiento significativo de las bases teóricas de ésta fue encontrar en la satisfacción de determinados intereses colectivos una fuente de bienestar, lo que vendrá en apoyo de nuestra hipótesis.

\section{El esquema teórico de Viner}

El razonamiento de Viner se puede resumir de la siguiente manera: sea el caso de una unión aduanera perfecta para lo cual no se toman en consideración aspectos "administrativos", como los denominó Viner, vgr. el mecanismo de distribución de los ingresos aduaneros entre los países pertenecientes a la unión y la existencia de un código aduanero uniforme, entre otros. Se suponía también que los dos países ( $A$ y $B$ ) tienen los mismos aranceles de importación, las empresas operan a costos constantes, los de transporte son nulos y los mercados son de competencia perfecta, en los cuales los bienes están tipificados y, por tanto, es indistinto para el consumidor de quién los adquiere. Dos situaciones básicas cabe considerar: en la primera, los países $A$ y $B$ producen la mercancía $X$ bajo protec-

\footnotetext{
Ibid.

10 Ernesto Serepanti y Stefano Zamagni, Panorama de historia del pensamiento económico, Barcelona, Ariel, 1997, pp. 158 159 .

11 A.C. Pigou, The economics of welfare, citado en Diccionario de economía política, Madrid, Castilla, 1962. Hay traducción española, La economía del bienestar, Madrid, Aguilar.
} 
ción arancelaria, siendo el país $A$ el menos eficiente de los dos (por que tiene costos más altos). Ninguno de los dos países importa la mercancía $X$ porque en ambos su precio es menor que el de cualquier fuente extranjera más el arancel. Al constituirse la unión aduanera y anularse los aranceles entre los miembros de la unión el país A comenzará a importar desde el país $B$. Por consiguiente, entre ambos países tendrá lugar una creación de comercio pues el lugar de la producción se habrá desplazado desde la fuente de costo más alto a la de costo más bajo en la unión.

Una segunda situación es la siguiente: el país $A$ no produce la mercancía $X$ pues el país $C$ puede vendérsela a un precio más bajo aun incluyendo el arancel de $A$. El país $B$ tiene costos menores que $A$ pero más altos que el país $C$, no obstante puede producir $X$ bajo protección arancelaria. Al constituirse la unión aduanera y anularse los aranceles entre los miembros de ésta, el país $A$ importará por primera vez desde el país $B$ desplazando a $C$, su antiguo proveedor no miembro de la unión el cual seguirá afectado al pago de un arancel. Se habrá operado una desviación de comercio desde el país $C$ al país $B$. Sencilla como es esta presentación resume adecuadamente el planteamiento de Viner.

Según este autor, "el objetivo fundamental de una unión aduanera, y su consecuencia principal, para bien o para mal, es el desplazamiento de las fuentes de abastecimiento, y el desplazamiento puede ser hacia fuentes de costo más bajo o más alto, según las circunstancias". ${ }^{12} \mathrm{Si}$ el movimiento se opera hacia una fuente de costo monetario menor, la unión aduanera constituye un movimiento hacia el libre comercio; en caso contrario, la unión aduanera resulta ser "un instrumento para lograr que la protección arancelaria resulte más eficaz". ${ }^{13}$

Por consiguiente, Viner concluía que a priori no es posible determinar cuál será el resultado final de la unión; todo depende de la forma que ésta asuma en la práctica, conclusión que divergió por completo de la idea hasta entonces prevaleciente según la cual las uniones aduaneras siempre aumentan el bienestar. Por el contrario, según Viner, cuando en el intercambio dentro de la unión aduanera predomina la creación de comercio, "uno de los miembros, por lo menos, debe beneficiarse; ambos pueden beneficiarse; los dos juntos deben obtener un beneficio neto; y el mundo en conjunto se beneficiará". ${ }^{14}$ Cuando lo que predomina es la desviación de comercio, "por lo menos uno de los países miembros resultará inevitablemente perjudicado; ambos pueden resultar perjudicados; los dos juntos pueden sufrir un perjuicio neto, al igual que el resto del mundo y el mundo en conjunto". ${ }^{15}$ Tal distinción de resultados revolucionó la teoría hasta entonces prevaleciente de las uniones aduaneras.

12 J. Viner, "Teoría económica de las uniones aduaneras, una aproximación al libre comercio", en op. cit., p. 92. El texto incluido es parte del capítulo iv de la citada obra de Viner.

Ibid., p. 91.

Ibid., p. 92.

$15 \quad$ Ibid. 


\section{Las contribución de las reinterpretaciones}

Al concretarse a considerar el efecto sobre el bienestar que tendría el desplazamiento de la producción desde el país de costos relativos mayores al país de costos relativos menores dentro de la unión, Viner tuvo en cuenta solamente la eficiencia de la producción (que se traduce en creación de comercio), y la eficiencia de la protección arancelaria (que da origen a la desviación de comercio). En sus palabras: "Si la unión aduanera es un movimiento hacia el libre comercio debe ser predominantemente un movimiento hacia bienes abastecidos de fuentes de menor costo monetario que antes. Si la unión aduanera tiene el efecto de desviar las compras hacia fuentes de costo monetario mayor, será entonces un instrumento para lograr que la protección arancelaria resulte más eficaz". ${ }^{16}$

A esta conclusión opuso Lipsey el argumento de que si bien "la creación de comercio y la desviación de comercio es fundamental para la clasificación de los cambios en la producción derivados de una unión aduanera, no pueden basarse en ella conclusiones de bienestar". ${ }^{17}$ En primer lugar, la pérdida de valor es absoluta sólo si lo que se tiene en cuenta es el desplazamiento de la producción del mismo bien de un país a otro, pero el desarrollo de la teoría reveló que no es así. Al crearse una unión aduanera, unos aranceles se reducen o eliminan mientras otros suben de nivel y en consonancia con estas variaciones cambian los precios relativos en el mercado, unos bienes se hacen más accesibles mientras otros se encarecen. Hay, por tanto, una sustitución de unos por otros como resultado de los cambios en los precios relativos.

La primera innovación al planteamiento original de Viner fue, precisamente, incluir los efectos de la unión aduanera en el consumo, pues al guardar silencio sobre los efectos en el consumo, este autor dejó implícita la existencia de una demanda invariable, aunque se resistió a admitirlo. En una carta de Viner a W.M. Corden, le manifestó que en forma explícita "o por implicación consciente" 18 no había supuesto que los bienes objeto de intercambio se consumieran en proporciones fijas, lo que equivale a aceptar que en forma implícita él había considerado que el consumo de los bienes variaba en razón de los cambios en los precios relativos provocados por la unión aduanera. Pero si tal fuera el caso todos los autores que comentaron a Viner habrían interpretado incorrectamente su obra, lo que no es creíble. Su carta parece ser más bien una enmienda a posteriori que, sin embargo, no introdujo explícitamente en nuevos escritos. Sobre el particular Krauss comentó que: "tras de volver a leer con atención el capítulo 4 de Viner no puedo encontrar ningún supuesto que permita tal conversión de los efectos de consumo en efectos de producción. En consecuencia, he adoptado la interpretación tradicional según la cual Viner no consideró los efectos de consumo, o sea, que supuso proporciones fijas de consumo". ${ }^{19}$

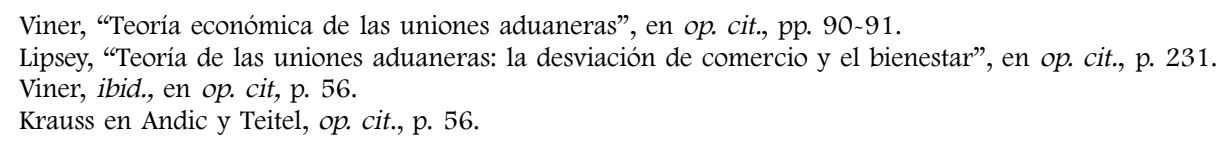


Un paso más se dio con el argumento de Lipsey de que el cambio de los precios por efecto de la unión aduanera influye no sólo sobre la eficiencia de la producción sino también en el aumento del consumo de los bienes producidos dentro de la unión, lo que se traduce en una reducción de sus importaciones del resto del mundo. ${ }^{20}$ Lipsey propuso distinguir entre efectos de producción y efectos de consumo de la unión, pero como a su vez los cambios en el consumo provocan cambios en la producción, dicho autor juzgó que era mejor distinguir entre sustitución de países y sustitución de bienes..$^{21}$ Lo primero sería por efecto de la creación y desviación de comercio y lo segundo por efecto del cambio de los precios relativos.

Del análisis anterior H.G. Johnson ${ }^{22}$ derivó la conclusión al considerar que era mejor definir los términos de creación y desviación de comercio de modo que impliquen tanto los efectos de producción como los efectos de consumo. Viner aceptó este punto de vista en la carta a Corden antes mencionada, y éste lo hizo suyo por considerar que sólo hay dos tipos de fuerzas contrarias en acción: el efecto de libre cambio cuando hay creación de comercio y el efecto de protección de la unión aduanera cuando hay desviación de comercio, ${ }^{23}$ distinción que Viner ya había hecho, como quedó indicado anteriormente.

\section{Balassa y otros argumentos}

Bela Balassa resume lo expuesto de la siguiente manera: "mientras la eficiencia productiva resulta afectada por la sustitución entre fuentes de oferta de la misma mercancía, la eficiencia en el intercambio está relacionada con la sustitución entre bienes de consumo de distinta especie". ${ }^{24}$

¿Porqué de distinta especie? Veamos enseguida una versión simplificada del ejemplo numérico que utiliza Lipsey y luego la explicación correspondiente.

Los países $A, B$ y $C$ producen la mercancía $X$ a razón de 35, 26 y 20 dólares, respectivamente. El país $A$ cobra un arancel de $50 \%$ y, por tanto, antes de la unión aduanera lo importa del país $C$, pues de este modo el precio interno es 30 dólares. No lo importa del país $B$ porque con el arancel el precio interno de $X$ sería 39 dólares. Al formar el país $A$ una unión aduanera con el país $B$, este último ya no paga el arancel. Por consiguiente, en lo sucesivo dominará el mercado de la unión pues produce $X$ al precio ya indicado de 26 dólares. Se trata de un caso de desviación de comercio pues se desplazó del mercado de la unión al país $C$ que tiene el costo más bajo, pero sigue afectado por el arancel de $50 \%$. No obstante que hay desviación de comercio, según Lipsey se incrementará el bienestar. ¿Por-

\footnotetext{
Lipsey, en op. cit., p. 231.

Lipsey, "La teoría de las uniones aduaneras, una reseña general", en op. cit., p. 43.

H.G. Johnson, "The Economic Theory of Customs Union", en Money, Trade and Economic Growth, Londres, George Allen and Unwin, 1962, pp. 46 73, citado por M.B. Krauss, op. cit., p. 59.

Citado por M.B. Krauss, op. cit., p. 60.

24 Bela Balassa, Teoría de la integración económica, México, uтeнA, 1980, p. 63.
} 
qué? Porque se trabaja con la hipótesis de que las tasas de sustitución de los bienes en el consumo y de transformación de los recursos en la producción, son iguales. Los mismos 35 dólares de materias primas que utilizaba el país $A$ para producir $X$ ahora los destina para producir la mercancía $Y$, que exporta al país $B$. En cambio, importa de este país la mercancía $X$ a razón de 26 dólares, de manera que con una unidad de $Y$ que exporta puede adquirir 1.346 unidades de $X$ (esto es, $35 / 26=1.346$ ) Ahora bien, 0.346 x $\$ 26=\$ 9$, que era la diferencia de precio de la mercancía $X$ producida en $A$ respecto de la que producía $B(\$ 35$ - \$26 = \$9) En otras palabras, al especializarse sale ganando cada país, $B$ porque aumenta la producción de $X$, y gana también $A$ pues obtiene la ganancia ya indicada dedicándose a producir $Y{ }^{25}$

La hipótesis de Lipsey y Gehrels fue objetada por Melvin, ${ }^{26}$ quien afirma que no hay ninguna razón para creer que el país A podrá comerciar en los términos de intercambio del país $B$. A juicio de Melvin, "la posición de equilibrio (en el comercio) se determinará conjuntamente por las condiciones de demanda de los dos países". ${ }^{27}$ Asimismo, Melvin hace notar que si en el país $B$ la oferta es limitada, la demanda nueva que le hará el país $A$ al constituirse la unión aduanera aumentará el precio de los bienes en $B,{ }^{28}$ lo cual constituye una razón más en contra de la hipótesis de que la similitud de las tasas de sustitución de los bienes en el consumo y de transformación de los recursos en la producción son iguales.

\section{Otras reinterpretaciones}

Utilizando modelos de equilibrio general, diversos autores enfocaron su atención en la distribución de los beneficios entre los países miembros de la unión y entre éstos y los no miembros y llegaron a la conclusión de que el país que antes de la unión tuviera comercio con su futuro socio probablemente ganaría con ésta, mientras que los miembros que con anterioridad tenían muchos intereses comerciales con el resto del mundo, perderían, a menos que pudiera mejorar sus términos de comercio con el resto del mundo mediante una desviación de comercio de tal manera que le permitiera compensar la pérdida neta sufrida por el cambio de proveedores. La mejoría de los términos de intercambio depende, sin embargo, del tamaño relativo de la unión con relación a terceros países.

Por su parte, Pearce ${ }^{29}$ indicó claramente que el propósito de las uniones aduaneras es redistribuir el ingreso mundial a favor de los países miembros gracias a un mejoramiento de los términos de intercambio con el resto del mundo. Conclusión que contradice el

25 Se eliminaron los conceptos técnicos para hacer más comprensible el razonamiento de Lipsey. Veáse Lipsey, op. cit., p. 35.

26 J.R. Melvin, “Comentarios sobre la teoría de las uniones aduaneras" en op. cit., pp. 248 255.

27 Ibid., p. 254.

$28 \quad$ Ibid., véase nota 9 en p. 252.

29 I. Pearce, International Trade, 1970, citado por Alfred Tovias, "A survey of the theory of economic integration", Revue d' Iintegration Européan/Journal of European Integration, año xv, núm. 1, Canadá, 1991. Agradecemos al profesor Tovias habernos enviado desde Jerusalén una copia de su valioso artículo en noviembre de 1998. 
principio neoclásico de la preferencia por el desmantelamiento arancelario unilateral no discriminatorio, cuyo resultado, argumentaba Pearce, conduce a un deterioro de los términos de intercambio y no a su mejoría. Según este autor, la formación de uniones aduaneras puede ser particularmente aconsejable para los países pequeños que individualmente no tienen influencia en los términos de intercambio, mientras que si forman parte de una unión aduanera los países pueden hacer con sus socios lo que no pueden hacer solos.

Como se recordará, según Viner, las uniones aduaneras podían incrementar el bienestar mundial en unos casos y en otros afectarlo negativamente si el resultado de la unión fuera crear comercio o desviarlo de la fuente de origen de costos monetarios más bajos, pero Kemp y Wan $^{30}$ reinterpretaron el planteamiento original vineriano argumentando que la unión aduanera tendría siempre una contribución positiva al bienestar mundial si el país que fuera beneficiado por la unión compensaba las pérdidas de los otros miembros e igualmente de los no miembros, y aún así estar mejor. Lo anterior era posible por dos vías conjuntas, la primera, mediante la transferencia de sumas globales dentro de la unión, y la segunda, mediante la elección del Arancel Externo Común apropiado, en vez de suponer que éste sería igual a los aranceles vigentes antes de la unión o al promedio aritmético de los aranceles de los miembros de la unión antes de que ésta se formara. Más aún, si se hace un manejo adecuado y oportuno del arancel común, podría eliminarse cualquier desviación de comercio y de igual manera cualquier efecto en los términos de intercambio. "De esta manera - comenta Tovias—, desde mediados de los años setenta el optimismo teórico reingresó por la puerta trasera: después de todo las uniones aduaneras no eran criaturas irracionales, incluso si, como lo demostró Berglas años más tarde, en ausencia de distorsiones locales cualquier cosa que los países miembros pudieran ganar por el comercio preferencial podía ganarse mediante el desmantelamiento unilateral de los aranceles". ${ }^{31}$

Años más tarde Krugman llegó a una conclusión más radical. Tomando en consideración que el poder de negociación y de tomar decisiones aumenta como resultado de que la unión aduanera hace posible la acción conjunta de los países miembros, Krugman argumentó que era de esperar que el Arancel Externo Común de la unión aduanera fuera más elevado que los aranceles de cada país por separado antes de ésta. En abierta contradicción con Kemp y Wan, para quienes la unión aduanera podría tener siempre efectos positivos gracias a que el manejo adecuado del arancel común eliminaría las desviaciones de comercio, la conclusión de Krugman fue que las uniones aduaneras siempre tendrán un efecto de desviación de comercio y que, en consecuencia, lo más probable sería que las uniones aduaneras redujeran el bienestar de los países no miembros y en algunos casos el propio bienestar mundial.

M. Kemp y H. Wan, "An elementary proposition concerning the formation of customs union", Journal of International Economics, 1976, citado por A. Tovias, ibid.

31 Tovias, op. cit. 


\section{Una salvedad necesaria}

Sin discutir el argumento en lo que toca a los países desarrollados, no es creíble que la unión aduanera de los países en desarrollo reduzca el bienestar de los países desarrollados, pues en lo individual los primeros, y a veces el conjunto de ellos, son económicamente muy pequeños para que la sustitución de importaciones pueda afectar el bienestar de sus proveedores. La excepción serían los acuerdos de integración de países en desarrollo que como conjunto integrado tengan poder monopólico en alguno o algunos rubros esenciales para la economía desarrollada.

Seguramente conclusiones del género de la que hizo Krugman, con mayor razón que las otras que hemos reseñado, tuvo un agrio sabor para el paladar neoclásico, cuya conclusión lógica, como Berglas y otros autores lo habían hecho con anterioridad, sería volver la espalda a las uniones aduaneras y elegir la opción siempre disponible de reducir a cero las barreras arancelarias de manera unilateral e incondicional, precio considerado razonable para alcanzar el óptimo bienestar. Hay que reconocer que de acuerdo con su esquema teórico tendrían razón. El razonamiento neoclásico, en general, se distingue por la coherencia abstracta de sus distintos elementos, los cuales se vinculan unos a otros con una secuencia de causa a efecto inexorable. Lo único que falta en ellos es el ser humano. El hombre y sus obras. Es lo que encontró a su paso Paul Krugman. Y lo que Argentina encontró al final del siglo xx: la perfecta secuencia teórica de las medidas tomadas conjuntamente por Menem y el FMI, que debían llevarla a la prosperidad, la llevaron, sin embargo, al desastre de su economía.

\section{El distanciamiento inicial}

Hasta aquí se ha pasado revista a la teoría tradicional de las uniones aduaneras a partir de quien sentó sus bases, Jacob Viner, comentado por una sucesión de autores, cada uno de los cuales encontró en los postulados del gran maestro una forma de reinterpretarlos. El interés de la teoría siguió centrado en el análisis de los efectos de las uniones aduaneras en el bienestar mundial. Había algo, sin embargo, que ni al maestro ni a sus continuadores les pasó por la cabeza darle una respuesta, considerando quizás que así son las cosas, o sea, como se dice en forma técnica, tomándolas como un dato.

La cuestión era sencilla en su realidad. Puesto que, de acuerdo con la economía neoclásica la existencia de libre comercio es la condición para alcanzar el máximo de bienestar mundial, la creación de uniones aduaneras contradecía por su base la argumentación vineriana, pues la unión aduanera limita la liberalización del comercio exclusivamente a los miembros de la unión. La respuesta salomónica a tal dilema fue argumentar que si bien las uniones aduaneras se apartaban del principio del libre comercio, al fin y al cabo resultaban ser un movimiento en esa dirección. 
El dilema siguió planteado, ¿por qué si el objetivo es maximizar el bienestar mundial todos los países cuentan con un sistema de protección arancelaria que discrimina los bienes, los países o ambos a la vez? Según la teoría económica neoclásica, los países no deben imponer restricciones arancelarias si tienen abierta la opción del libre comercio y, en caso de tener aranceles, no deben ingresar a las uniones aduaneras sino optar por una eliminación arancelaria unilateral. Y, sin embargo, ningún país se atiene a estos preceptos. He aquí la cuestión.

\section{Tres nombres y una sola orientación}

Tres nombres van unidos a la apertura de la teoría hacia nuevos horizontes: Harry Johnson, Charles Cooper y Benton Massell, cuyos artículos aparecieron en 1965. ${ }^{32}$ A partir de ellos, cuya contribución abrió cauces para nuevos enfoques, incluyendo más adelante el desarrollo económico, se operó la primera fractura en el esquema vineriano. Johnson cuestionó la aseveración neoclásica de que la imposición de aranceles constituye un acto irracional de los gobiernos. En un ensayo en que sentó las bases de su teoría, Johnson introdujo en el análisis de las uniones aduaneras la noción de preferencia colectiva por la producción industrial, que pasó a considerarse un bien de consumo colectivo, un bien público para cuya satisfacción el electorado podría demandar a su gobierno que destinara recursos para aumentar la producción y el empleo industrial más de lo que éstos aumentarían en un sistema de libre competencia internacional. Lo anterior, claramente llevaba a considerar el bienestar mundial en términos sociales y no individuales, lo que conlleva un distanciamiento de la teoría noclásica de uno de sus fundamentos. Bajo ciertas condiciones, razonaba Johnson, los gobiernos podían ver las uniones aduaneras como una estrategia para maximizar el bienestar, en cuyo caso "la unión aduanera genera un aumento del bienestar a causa de su capacidad de satisfacción de la demanda de consumo público a un costo menor en términos del consumo privado, sacrificado por la reasignación de recursos internos del sector menos eficiente que compite con las importaciones al sector más eficiente de las exportaciones". 33

De acuerdo con Johnson, la preferencia por la producción industrial se originaba en diversas fuentes como podían ser las "aspiraciones y rivalidades nacionalistas frente a otros países, el poder de propietarios y trabajadores de instalaciones industriales para lograr una redistribución del ingreso a su favor mediante medidas políticas o la creencia de que la actividad industrial tiene efectos externos benéficos de varias clases". ${ }^{34}$

\footnotetext{
32 Harry G. Johnson, Teoría económica del proteccionismo, la negociación arancelaria y la formación de las uniones aduaneras, 1965; Charles Cooper y Benton Massell, "A New Look at Customs Union Theory", Economic Journal, 75, 1965, en op. cit.

33 Johnson, citado en op. cit., p. 19.

$34 \quad$ Ibid., p. 330.
} 
Por su parte, Cooper y Massell argumentaron que una política arancelaria no discriminatoria constituía un instrumento de liberalización del comercio exterior más eficiente que las uniones aduaneras, por lo que la razón para constituirlas no podía ser la asignación más eficiente de recursos, como se argumentaba. Para ellos, la integración comercial debe entenderse como un mecanismo especial de protección que hay que comparar con otros medios alternativos, y no como un medio para liberalizar el comercio. Hacía falta, por consiguiente, una teoría de la protección arancelaria y para echar sus cimientos ambos autores hicieron importantes contribuciones.

Cooper y Massell fueron más lejos y argumentaron que en los últimos quince años se había elaborado "un aparato teórico impresionante" sobre el efecto de las uniones aduaneras en países económicamente desarrollados, pero no se contaba con un cuerpo teórico comparable que pudiera aplicarse a los países en desarrollo. Al igual que Johnson, ambos autores se apartaron del criterio de que el bienestar está vinculado exclusivamente al consumo privado de bienes y servicios y consideraron que "uno de los objetivos principales de la integración económica entre países menos desarrollados es el fomento del desarrollo industrial y la orientación de tal desarrollo de acuerdo con lineamientos más económicos". ${ }^{35}$ Así, el objetivo de la política económica y la preferencia social por la industrialización pasó a ser un bien público que debía ser promovido por el Estado. Por tanto, la cuestión esencial era preguntarse cómo podía emplearse de la mejor manera la protección, cómo hacerla más eficiente, cual era el medio más conveniente para promover la industrialización (aplicación de aranceles, otorgamiento de subsidios a la producción o la exportación, reintegro de derechos de importación sobre las materias insumidas en la producción de bienes exportables, entre otros).

Finalmente, Johnson planteó con mucha anticipación un problema que en la literatura sobre integración económica latinoamericana ha estado presente con bastante frecuencia: el desarrollo equilibrado de los países que participan en un acuerdo de integración. El destacado teórico señaló que para la teoría tradicional el objetivo de la unión aduanera es elevar la eficiencia de la producción, independientemente del país donde ésta tenga lugar, mientras que la hipótesis de la preferencia por la producción industrial implica que todo acuerdo de unión aduanera debe incluir disposiciones tendientes a asegurar que cada miembro obtenga una "parte justa de la producción industrial y, en particular, que el crecimiento de la producción de la unión no se concentre en uno o en pocos países a costa del resto". ${ }^{36}$ Justamente eso fue lo que persiguieron los procesos de integración entre los años sesentaochenta, con la excepción de la ALALC; ese fue el planteamiento original que hizo la CEPAL a Centroamérica en 1952, y fue además el objetivo principal de la programación indus-

$35 \quad$ Ibid., p. 369

$36 \quad$ Ibid., p. 363. 
trial del Grupo Andino en los años setenta del siglo pasado. Lo que no se alcanza a comprender del todo es por qué se dice que la preferencia por la producción industrial debe incluir, en las uniones aduaneras, disposiciones para evitar que la producción se concentre en uno o en pocos países a costa del resto. Sin duda, esto es lo deseable pero no es una condición natural, intrínseca de la preferencia por la producción industrial. Dada esta preferencia, los países deciden formar la unión aduanera como el medio para darle viabilidad; cada país abriga esa preferencia, por eso se unen, pero es una decisión política, por tanto exterior a la unión, que la industrialización se distribuya territorialmente en forma equitativa, y no una implicación necesaria de la opción industrial. El comentario no resta de ninguna manera importancia al penetrante razonamiento de Johnson.

\section{El análisis de Andic y Dosser}

Un desarrollo posterior de la teoría en la nueva orientación se debe a F. Andic, S. Andic y D. Dosser. ${ }^{37} \mathrm{~A}$ juicio de estos autores habría dos corrientes de pensamiento en el enfoque no tradicional de las uniones aduaneras: una concedería la principal importancia a la industrialización como objetivo de la unión, y la otra destacaría el ahorro de divisas escasas mediante la sustitución de importaciones. Los autores citados integran ambos enfoques argumentando que los países en desarrollo sean tanto la industrialización — que permite la sustitución de manufacturas - como el ahorro de divisas por ser ésta una de las más importantes restricciones para la formación de capital. El argumento se desarrolla, en lo fundamental, como se indicará enseguida.

De acuerdo con la teoría neoclásica de las uniones aduaneras, como la denomina Staffan Linder, si hay creación de comercio el ingreso nacional aumenta gracias a la especialización (el país miembro de la unión que tiene el menor costo domina por completo el mercado); por el contrario, la desviación de comercio origina una pérdida de ingreso nacional. No obstante, los países que forman una unión aduanera pueden optar por esta pérdida de ingreso nacional si a cambio de ello se industrializan. La elección implica que en su escala de valores tiene más importancia la industrialización que las importaciones de bienes industriales de fuentes externas de menor costo - al constituirse la unión aduanera; no necesariamente en todo momento- La observación es válida, sin embargo, para la teoría neoclásica de las uniones aduaneras es irrelevante, pues su enfoque es estático.

De igual manera, la pérdida de ingreso nacional debido a que se incurre en desviación de comercio puede contrarrestarse con el ahorro de divisas, gracias a la sustitución de importaciones (no sólo de productos industriales sino igualmente de otros bienes y servicios).

${ }_{37}$ Fuat Andic, Suphan Andic y D. Dosser, "Una contribución a la teoría de la itegración económica", en op. cit. 
No obstante que el ahorro de divisas no está necesariamente vinculado a la industrialización, Andic y Dosser identificaron un rasgo común a ambos objetivos, a partir del cual construyen su modelo. La cuestión es la siguiente: cada actividad orientada a ahorrar divisas tiene un costo en términos de ingreso nacional sacrificado y un beneficio en términos de divisas ahorradas. De igual manera, cada industria implica un costo y un beneficio en términos de crecimiento. Así, pues, la evaluación de la conveniencia de una política de industrialización que incluya el objetivo de ahorrar divisas no debe hacerse solamente considerando los costos sino determinando una razón de costo-beneficio, de lo que resultaría que una determinada actividad debe promoverse si dicha razón es mayor que uno; si el beneficio es mayor que el costo.

El análisis de los autores comentados llega, finalmente, a la conclusión de que, a diferencia del modelo tradicional, podría darse el caso de una unión aduanera en que ciertas actividades (o industrias) gozarían de libre comercio dentro de la unión, mientras otras seguirían desenvolviéndose en un régimen de libre comercio con el resto del mundo. En otras palabras: el concepto tradicional de unión aduanera implica libre comercio irrestricto dentro de la unión y un arancel externo común para las relaciones con el resto del mundo. Aún más, según Staffan Linder, la unión aduanera de países en desarrollo debe aplicar el principio neoclásico de distribuir las industrias de acuerdo con sus ventajas comparativas, en tanto que Andic y Dosser opinan que esta regla de distribución debe limitarse en el caso de que un miembro de la unión aduanera quedara desprovisto de industrias debido a que otro miembro concentra razones de costo-beneficio más bajas (el costo menor en término de creación y desviación de comercio).

En resumen, el modelo que se ha venido considerando presupone el examen sector por sector de actividad mediante un cálculo de desarrollo, según la expresión utilizada por sus autores, lo que arroja resultados diferentes a los que se obtendría mediante otros enfoques, sean o no tradicionales.

A modo de conclusión final, Andic y Dosser resumen así los resultados de su argumentación: "la creación de comercio y la desviación de comercio son términos engañosos en el contexto de los países menos desarrollados, ya que se han derivado de la teoría convencional del costo comparativo. Lo que una unión aduanera del tipo aquí bosquejado elevada al máximo es la creación de desarrollo, y no la creación de comercio, y lo que reduce al mínimo es la desviación del desarrollo, que significa desviar la capacidad potencial de desarrollo hacia un país ya desarrollado". ${ }^{38}$

38 Andic, Andic y Dosser en op. cit., p. 409. 


\section{El distanciamiento final}

Como se ha dicho antes, uno de los supuestos básicos del análisis de Viner fue la producción a costos constantes, pero precisamente un argumento para constituir las uniones aduaneras es beneficiarse del incremento de la producción, y por tanto, de las economías de escala que hace posible la ampliación de los mercados al eliminar las barreras arancelarias entre los miembros de la unión. La economía de escala es simplemente un dato técnico y, como tal, varía su importancia de unas ramas industriales a otras en consonancia con el grado de complejidad de las tecnologías empleadas. En todos los casos, la producción masiva es superior en beneficios que la producción en reducida escala, pero mientras las industrias que utilizan tecnologías de baja o moderada complejidad relativa (el calzado, el vestuario, por ejemplo) son poco exigentes en cuanto a su escala de producción, las industrias de tecnología compleja y, en particular, la altamente especializada, como la electrónica, la automotriz, la de semiconductores, entre otras, pueden operar solamente a partir de un mínimo de producción, que es generalmente muy elevado.

De lo anterior resulta una conclusión casi obvia, dado el caso de una desviación de comercio, los países que producen a costos más elevados que sus tradicionales proveedores pueden suprimir el efecto de desviación ampliando la capacidad de producción, ahora posible porque el acuerdo de integración amplía la dimensión del mercado. En virtud de la economía de escala que introducen su producción se torna altamente competitiva.

El distanciamiento de fondo con las hipótesis neoclásicas de las uniones aduaneras es hoy día crecientemente mayor. Para comenzar, desde los años setenta Gruebel y Lloyd desarrollaron la teoría del comercio intraindustrial con base en la observación de lo que venía ocurriendo en el comercio exportador-importador de la entonces Comunidad Europea. Lo anterior significa que en vez de ser el comercio internacional interindustrial, es decir, de productos provenientes de ramas industriales diferentes - tal como lo anticipaba la teoría tradicional del comercio internacional-, el comercio intraindustrial se caracteriza por el intercambio de productos de la misma especie, iguales pero diferentes en una de sus características o por el prestigio de una marca u otras razones de parecida índole. Gruebel y Lloyd conjeturaron que el comercio intraindustrial era posible gracias a que las empresas se concentraban en un modelo o en una línea específica de producción una vez que tenían la certeza de que gozarían de un cuasimonopolio en el mercado de la Comunidad para la rama de producción elegida. El argumento es válido, pero, por otra parte, es fundamental explicar el comercio intraindustrial como consecuencia de la revolución tecnológica que ha tenido lugar desde la segunda mitad del siglo xx.

Otro importante avance metodológico fue la asociación de la teoría de la organización industrial y la teoría del comercio, la llamada nueva teoría del comercio internacional, que incorpora los rendimientos crecientes a escala, la competencia imperfecta y la diferenciación de productos. La incorporación de estos elementos dio pie para explicar la 
existencia de procesos productivos transnacionales, la denominada producción internacional integrada consistente en el desmembramiento de la cadena de valor entre diversas empresas geográficamente dislocadas, pero bajo principios de organización geográfica de la producción altamente centralizada por las empresas transnacionales, bajo cuyo control se encuentra el nuevo sistema. "El argumento básico es que para cierto tipo de productos la integración vertical internacional de los procesos productivos puede ser una precondición para la eficiencia productiva", ${ }^{39}$ y lo es gracias a la disposición de tecnologías avanzadas, particularmente la computación y las comunicaciones.

El nuevo sistema implica además una creciente importancia del comercio intrafirma. En las industrias farmacéutica, de computadoras, semiconductores y automóviles un estudio de la OCDE encontró que el comercio intrafirma es superior a 50\% del total de las transacciones internacionales de las empresas. ${ }^{40}$ En razón de su gran tamaño la empresa transnacional tiene la condición privilegiada de internalizar muchas transacciones que habitualmente se realizan en el mercado. La poderosa ola de compras y fusiones de las grandes empresas, que ha llevado a muy alto grado la oligopolización del mercado internacional en los últimos años, lleva aparejado un incremento también elevado del comercio intrafirma.

\section{Tentativa de conclusiones}

Nada de lo expuesto en los párrafos anteriores tiene relación alguna con la teoría neoclásica de las uniones aduaneras. El distanciamiento total se ha consumado. De la misma manera que al cobrar vida el liberalismo económico las economías que tuvieron ante sí Adam Smith y los otros autores que Marx agrupó para siempre en la categoría de clásicos, ${ }^{41}$ era una economía en que predominaba la competencia perfecta, pero dejó de serlo hacia fines del siglo XIX, así la economía que tuvo bajo su consideración Jacob Viner era otra muy distinta de la contemporánea. Viner fue sin duda un destacado pensador. Sólo el que desafía el paradigma imperante de una época lo es. Abrió todo un periodo de investigación que no transcurrió en balde. Siempre algo queda como producto de los desarrollos teóricos por parte de quienes son adherentes o de quienes disienten. También la discrepancia es creativa. Pero no cabe duda de que hoy la teoría neoclásica de la integración, como en general la teoría tradicional del comercio internacional, son impotentes para explicar el proceso de la Unión Europea, el Tratado de Libre Comercio de América del Norte o el Área de Libre Comercio de las Américas.

\footnotetext{
39 CEPAL, Os agentes económicos em processos de integração; inferencias para avaliar os efeitos da ALCA, Brasil, 2002, p. 3. Documento elaborado por Renato Baumann y Francisco Galrão Carneiro.

40 OCDE, Globalization of industry. Overview and sector reports, París, 1996, citado por CEPA, op. cit.

41 Serepanti, op. cit.
} 
Antes de Viner, la teoría de la integración no tenía identidad propia. Es probable que cuando se cuente con una síntesis de la experiencia actual, la que hasta ahora comenzamos a vivir, esa identidad se diluya en una teoría que ya no tendrá base económica exclusivamente sino sintetiza a su vez la contribución de otras ciencias sociales. Más aún, es convicción del autor de estas notas que la integración económica regional deberá desarrollarse en estrecha relación con la teoría del desarrollo, y ello mismo implica la incorporación de los aportes de otras ciencias sociales.

(9)

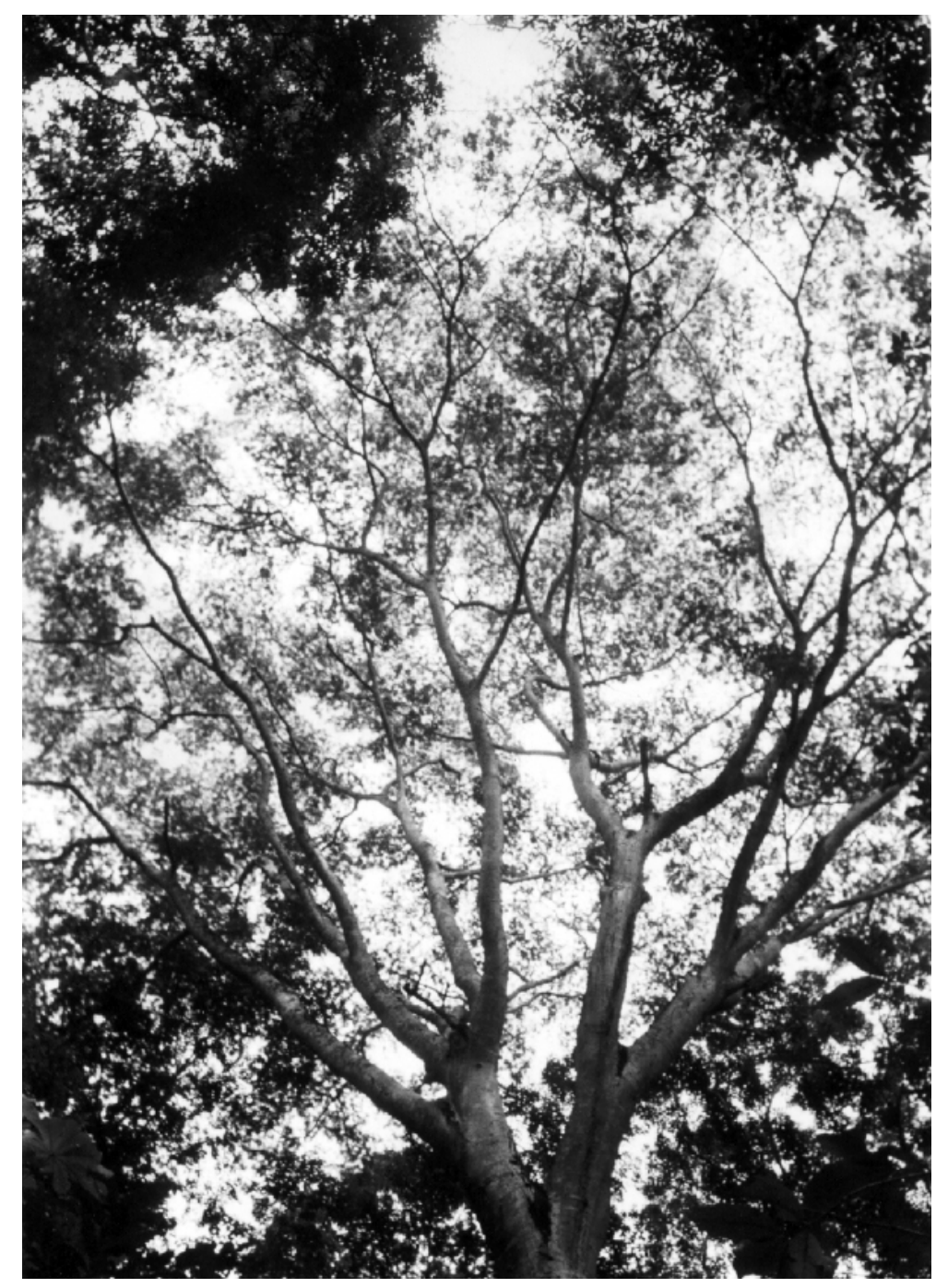

Rumbo a Copalitilla, Oaxaca, México, agosto de 2003 (P.A.I.). 